\title{
Sosyo-Politik Düzenin Koşulu Olarak İnsan Doğası
}

\author{
Human Nature as a Condition for Socio-Political Order
}

\section{Eray YAĞANAK*}

Öz: Bu makalede, temel olarak, bir devletin bürokratik yapısını oluşturan kurumlar ve devletin temeli olan toplumsal yapı arasındaki uyumun "insan doğası" kavramıla doğrudan bir ilişkisi olduğu iddia edilecektir. Siyaset Bilimi insanın rasyonel ya da duygusal davranışlarının siyasal düzenin kurgulanışında ve işleyişinde önemli bir yeri olduğu iddiasıyla çağdaş psikolojiden yararlanmıştır. Ne var ki, siyaset biliminin insan zihni ve doğası hakkında felsefi bir incelemeye girişmeden kurgulamaya çalıștı̆ı siyasal düzenler sözü edilen uyumun sağlanması konusunda yetersiz görünmektedir. Sosyo-politik düzen ve uyumun kendisini en üst derecede görünüşe çıkardığı varsayılan batı demokrasilerinde, kendilerini mevcut politik düzenin bir parçası olarak görmeyen insanların hoşnutsuzluğu çağdaş siyaset biliminin insanı sadece psikolojik davranış kuramları bağlamında ele almış olmasına, insan doğası ve siyaset arasındaki köklü ilişkiyi görmezden gelmiş olmasına bağlanabilir. Bu nedenle, bu makale, insan doğası ve siyaset arasındaki içkin (immanent) ilişkiyi siyaset bilimi değil, siyaset felsefesi açısından inceleyecek ve siyasal yapının hem kendi iç işleyişinde hem de toplumsal yapı ile ilişkisinde çatışmacı ve ayrıştırıcı olmayan bir uyumun ancak ve ancak bu ilişkiye gereken önemin ve dikkatin verilmesi ile mümkün olacağını iddia edecektir.

Anahtar Sözcükler: İnsan Doğası, Sosyo-Politik Düzen, Machiavelli, Hobbes, Locke

\begin{abstract}
This paper deals with human nature and the links human nature has to the creation of a coherent political or social order. It studies the implications that political science has on modern psychology, in the context of rational human behavior. However, in the modern context political science as a subject occupies an inadequate position within realms of the study of human mind and nature. Even though it is a general view that western countries with their democracies represent the highest form of socio-political order, those living within these countries often feel dissatisfied with their present form of working. This dissatisfaction has led to a growing interest in the functioning of the political institutions of a country, but there is very little attention paid to the links that exist between human nature and politics. Even though past studies on politics were inherently linked to the complexities seen in human nature, modern political researchers prefer to overlook this link, thereby disqualifying the field of psychology from bringing transformations in the arena of politics. This paper, which studies human nature and politics, finds that many of the problems that plague modern society undoubtedly arise from the various fallacies found in the nature of human reasoning.
\end{abstract}

Keywords: Human Nature, Socio-Political Order, Machiavelli, Hobbes, Locke

Dünyanın farklı yerlerinde farklı siyasal ideolojilere sahip ülkelerin hem kendi içlerinde hem de birbirleriyle olan ilişkilerinde görünüşe çıkan mevcut çatışmalar, bu ülkelerin yurttaşlarının

Yrd. Doç. Dr., Mersin Üniversitesi, Fen-Edebiyat Fakültesi, Felsefe Bölümü, Mersin. eray@mersin.edu.tr Makalenin bir bölümü "Human Nature, Ethics and Politics in the Philosophies of Thomas Hobbes and Immanuel Kant" adlı tamamlanmış doktora tezinden türetilmiştir. 
varoluşlarını hem ulusal hem de küresel bağlamda doğrudan tehdit etmektedir. Bunun en önemli nedenlerinden biri, bu siyasal ideolojilerin kuramsal dayanaklarının insan doğasına ilişkin bir inceleme çabasından yoksun olmalarıdır. Çünkü Wilson'un $(1996,478-498)$ da belirttiği gibi "insan doğası" dünya siyasetinde, hem ulusal hem de küresel bağlamda, karar mekanizmalarını etkileyen etkin bir güce sahiptir. Ancak "insan doğası" kolayca tanımlanamayan, zihinsel yetileri yerinde olan her insanın algılama, akıl yürütme, davranış, düşünme, duygu vb. özelliklerini içeren ve bu özelliklerden hareketle insanın içinde bulunduğu sosyo-politik yapıya ilişkin değerlendirmelerin kendisini görünüşe çıkardığı karmaşık bir yapıdır. Bu karmaşık yapının nasıl şekillendiği, ne türden nedensel ilişkilerin bu karmaşık yapıyı etkilediği, insanın düşünme süreçlerinin çatışmacı olmayan bir yapıya nasıl dönüştürülebileceği batı felsefesi içinde siyaset kuramının ve etiğin temel tartışma konularından biri olmuştur. Çünkü böylesi bir yapının mevcudiyeti, aynı zamanda, "iyi yaşam"1n da temel ölçütlerinden biri olarak görülmüştür. Burada dile getirilen iyi yaşam, yaşamı sürdürmeye olanak sağlayacak maddi kazanımlara sahip olmakla değil, Aristotelesçi anlamda, ancak ve ancak ruhun erdemleri ve aklın erdemleri arasında aşırılıktan uzak bir uyumun sağlanması ile olanaklı hale gelebilir. Bu, aynı zamanda, insanın varlık yapısına içkin olan varlığını sürdürme arzusunun temel dayanaklarından biridir.

İnsan doğası ve sosyo-politik düzen arasındaki ilişkinin açığa çıkarılması, öncelikle, "insan doğası" kavramı ile ne kastedildiğinin araştııılmasını gerektirir. Günlük dildeki kullanımıyla ele alındığında, sıradan insanlar için, akıl sahibi olma, iyi olma, erdemli olma, adil olma vb. kavramlarla tanımlanmaya çalışılan bu kavram üzerinde, anlam bakımından, bir uzlaşma olmadığı açıkça görülebilir. Bu uzlaşmazlığın temel nedeni, tanımlamaların tamamının bir "kişi” ye yönelik olmasıdır. Oysa "insan doğası kavramı kişiyi tanımlamaz, aksine, insan doğası tarihsel olarak insanın ne olduğuna ve onun nasıl davranması gerektiğine iliş̧kin yerleşik inançların cisimleşmiş haline" (Ruth 1990, 63) karş11ı gelir. Bu, aynı zamanda, yerleşik inançlara bağlı olarak farklı mekan ve zamanlarda insanın özünün ya da doğasının ne olduğuna ilişkin tanımlamaların farklılaşmasının temel nedenlerinden biridir. Çünkü "doğa ya da öz kavramına yüklenen anlamlar, yine belirli bir zaman ve mekanda varliğını sürdüren, ya belirli bir gurubun ya da bir bireyin bakış açısına ve deneyimlerine bağlıdır" (Ruth 1990, 70). Burada, insanın doğasına ilişkin bir perspektivizm savunusu yapma amacı değil, aksine, farklı tanımlamaların hepsinde ortak olan bir noktanın, insan doğası ile siyasal düzen arasındaki ilişkinin bu kavram üzerinden kurgulanıyor olduğunu açığa çıkarma amacı güdülmektedir. Bu nedenle, bu amaç, tarihsel bakımdan, sözü edilen ilişki bağlamında bir araştırmayı zorunlu kılar. Bu çalışmada, bu ilişki, Machiavelli, Hobbes ve Locke üzerinden ele alınacak ve insan doğası ve siyasal düzen arasındaki içkin ilişki gözler önüne serilmeye çalışılacaktır.

Algılama, akıl yürütme, davranış, düşünme, duygu ve benzeri özellikler insan doğasını tanımlayan temel özellikler olarak ele alındığında, bu özelliklerin tarihsel süreç içerisinde değişmeden kaldığını öne süren kuramlar, örneğin realizm, olduğunu görüyoruz. Bu kuramlar insanın "benci" bir doğaya sahip bir varlık olarak, genel anlamıyla, ahlaki olmayan davranışlara eğilimli olduklarını dile getirirler. Örneğin, Machiavelli'nin “bütün insanların kötülüğe eğilimli olduklarına" (Machiavelli 1970, 111) ilişkin iddiası onun insan doğasına ilişkin olarak dile getirdiği "nankör, vefasız, yalancı ve gerçeği gizleyen, tehlikeden kaçan ve kazanma hırsıyla dolu" (Machiavelli 1961, 66) tanımlamalarıyla yakından ilgilidir. Bu aynı zamanda, bir devlette egemenlik erkini elinde bulunduran kişinin yurttaşlarla olan ilişkisinin ve sosyo-politik düzenin hangi temeller üzerinden yükseldiğinin ya da yükselmesi gerektiğinin ifadesi anlamına gelmektedir. Machiavelli'nin ifadelerinde, bir toplumda düzenin sağlanması bağlamında, sadece mevcut yasaların uygulanması değil, aynı zamanda ahlaki içerimlerin de olduğunu görmek mümkündür. $\mathrm{O}$, bir bakıma, insanın sahip olduğunu varsaydığı doğayı ahlakın da bir parçası 
haline getirmekle, sosyo-politik düzenin sağlanması bağlamında, egemenin eylemlerinin meşru temellerini de atıordu.

İnsan doğas1, siyaset ve toplumsal düzen arasında derin bir ilişki olduğunu dile getiren Thomas Hobbes'un insan doğasına ilişkin düşünceleri oldukça karamsardır. Bu karamsar tutumdan hareketle Hobbes, insanın doğal durumunu herkesin herkese karşı savaş hali olarak tasvir etmiştir. Bu tasvirin temel dayanak noktası ise Hobbes'un insan doğasına atfettiği yalnızlık, kötülük, vahşiliktir. Bu özelliklerin insanda doğal olarak varolup olmadığı, bir başka deyişle, bunların insanın doğasına içkin olan özellikler olup olmadığı tartışması bir yana, Hobbes'u böyle bir varsayıma götüren temel itkinin varlığını sürdürme arzusu olduğu ileri sürülebilir. Varlığını sürdürme isteği ve bu isteğin yerine getirilmesine olanak sağlayacak güç istenci insan doğasına içkin temel bir varsayım olarak düşünüldüğünde bu varsayımı destekleyecek dişsal koşulların neler olduğunu anlamak zor olmasa gerek. Bu koşullardan en önemlisi, en azından Hobbes için, insanın sürekli olarak içinde hissettiği korku haline neden olan diğer insanlardır. Kaynă̆ 1 diğer insanlar olan korku, bir bakıma, bu korkunun bertaraf edilmesini sağlayacak güç istencinin ortaya çıkmasına neden olan temel itki olarak dile getirilebilir. Burada sözü edilen güç istenci, yaşamı sıradan bir şekilde sürdürmeye imkân sağlayan olanakların elde edilmesine karşılık gelmez, tersine insanın doğasına içkin olan çıkarlarını koruma ya da arzularını tatmin etmenin bir gereği olarak kendisini görünüşe çıkarır. Her insanda ortak olan bu arzu, aynı zamanda, potansiyel bir çatışma durumunun ortaya çıkmasına neden olan bir duruma karşılık gelir. Bu potansiyel çatışma durumu ya insanın sahip olduğu güç ile ortadan kaldırılır ya da herkesin herkese karşı olduğu bir savaş durumuna neden olur. Hobbes'un temel çıkış noktasını da oluşturan herkesin herkese karşı savaş durumunda olma hali onun siyasal düzen ve insan doğası arasında kurduğu ilişkiden ortaya çıkardığı devlet kuramının da temellerini açığa çıkarır. Bu, en başından beri insanın varlık yapısına ilişkin olarak dile getirdiği temeller üzerinde yükselir. Burada sözü edilen varlık yapısı, insanın varlığa nasıl geldiğine ilişkin bir duruma değil, insanın varlık yapısını oluşturan niteliklere karş1lık gelir. Bir başka deyişle, kastedilen şey şudur: Hobbes benimsediği doğa ve insan kavrayışı gereği, bir şeyin ne türden bir varlık olduğuna ilişkin araştırmasını o şeyi en küçük parçalarına ayırarak gerçekleştirme çabasına girer. $\mathrm{Bu}$ nedenle de insanın varlık yapısına ait temel nitelikleri anlayabilmesinin ilk koşulunun, De Cive'de dile getirdiği gibi, "onu oluşturan nedenlerin araştırılması" (Hobbes 1987, 32) olduğunu dile getirir. Aslında, Hobbes için, bu sadece insan için değil, insan da dahil olmak üzere araştırma nesnesi haline getirilen her şey için geçerlidir. $\mathrm{Bu}$ bağlamda, Hobbes, öncelikle insanı içinde bulunduğu doğal koşullara bağlı olarak ele alır ve mekanistik/determinist bir yaklaşımla insanın hem doğa ile hem de diğer insanlarla ilişkisini ortaya çıkarmaya çalışır.

Hobbes'a $(1991,14)$ göre, insanların birbirleri ve dış dünya ile ilişkileri nedensel ilişkiler ağının bir sonucu olarak gerçekleşir. Bir başka deyişle, "bir nesnenin varlığa çıkmasına olanak sağlayan nedenler o nesnenin başka bir nesne ile nedensel ilişsi içinde olmasında yatar". Hobbes'un bu açıklamasının oldukça önemli bir sonucu vardır. O bir taraftan insanın doğal bir varlık olduğunu ve bu nedenle de tüm eylemlerinin doğa yasaları tarafından belirlendiğini, diğer taraftan da doğanın nedensel ilişkiler ağının üzerine yükselebileceği bir yetisi olduğunu ileri sürer. $\mathrm{Bu}$ iki olguyu açıklamak üzere yaptığı ayrım, aynı zamanda, onun insanın ne tür bir doğaya sahip olduğunu ve sahip olduğu bu doğanın ona ne türden eylem olanakları sağladığını açıklama imkânı sağlar. Doğada hiçbir şeyin kendiliğinden hareket etme olanağına sahip olmadığını vurgulayan Hobbes hareketi iki biçimde açıklar. Doğanın kendi içindeki nedenselliği nesnelerin birbirleri ile etkileşimlerini açıklarken, Hobbes'un asıl üzerinde durduğu konu, insan eylemlerine içkin olan nedensellik ilişkileri ve bu ilişkilerin doğurduğu sonuçlardır. Yukarıda da 
dile getirdiğimiz gibi, Hobbes insanı da doğal koşulların bir parçası olarak görür ve bundan hareketle de insanın doğasına içkin olan iki tür hareketten, bir başka deyişle, eylem olanağından söz eder. Bu iki hareket tarzı Hobbes tarafindan hayati (vital) ve iradi (voluntary) hareket tarzları olarak belirlenir. Hayati hareket, kan dolaşımı, beslenme, nabız atması, nefes alma vb. hareketler olarak insanın doğumundan ölümüne kadar geçen süreyi kapsayan doğal bir işleyişe karşıllk gelir. Bu, doğada, doğal bir varlık olarak bulunan her canlı için olağan, bir başka deyişle, canlılığın koşulu olarak her bedende kendiliğinden ortaya çıkan bir durumdur. Hobbes'un insan doğası ve siyasal düzen arasında kurduğu ilişkinin kendini görünüşe çıkardığı hareket tarzı olarak iradi hareket, onun ne türden bir düzen tasarladığının ipuçlarını verir. Çünkü, ona göre, iradi hareketler, tüm insan eylemlerini etkileme özelliğine sahip ve kaynağı "insan zihninde harekete neden olacak bir önceki düşünceye dayanan" (Kavka 1986,18) hareket ya da eylem tarzları olarak tüm insani tutkuların ya da arzuların kaynağıdır. Burada dile getirilen tutku ya da arzu basit bir isteme duygusuna değil, tersine tüm rasyonel eylemleri yöneten bir duruma karşı1ık gelir. Bu durum, aynı zamanda, insanda kendini koruma güdüsünün ve güç istencinin de temeli olarak adlandırılabilir. Çünkü insanı eylemlerinden alıkoyacak, bir başka deyişle, insanın eylemde bulunma özgürlüğünü kısıtlayacak her tür dışsal etki iradi hareketlerin önünde insanın doğal olarak aşmak isteyeceği bir olgu durumuna işaret eder. $\mathrm{Bu}$ bağlamda, güç istenci eylemde bulunabilmenin, isteklerini diş engellemelere maruz kalmadan karşılayabilmenin temeli olan özgürlük arzusunun ya da bilincinin ortaya çıkmasının koşulu olarak karşımıza çıkar. Bir başka deyişle, güç istenci ve özgürlük birbirini destekleyen iki temel insani tutkuya (desire) karşı1ık gelir.

İnsanın doğal varlık yapısına ait bir özellik olarak eylemde bulunma özgürlüğü, doğal durumda varlığını sürdürme ereği taşıyan her insanda ortak bir özellik gösterir. Bu ortak özellik, aynı zamanda, doğal bir varlık olmak bakımından, her insan için doğal bir hak olarak tezahür eder. Bir başka deyişle, tekil olarak varlığını sürdürme ereği güden her tek insanda eşit bir biçimde ortaya çıkar. Bu eşitlik, aynı zamanda, her tek insanda, kendini koruma ve varlığını, dışsal bir tehdide maruz kalmadan, sürdürebilme arzusuna bağlı olarak herkeste bir savunma mekanizmasının ortaya çıkmasına neden olur. Doğal haklarını koruma arzusu güden her insan bir başkasını bu haklar üzerinde bir tehdit unsuru olarak görür. Daha da önemlisi, "herkesin her şey üzerinde herkes kadar hakkı olması onların birbirleri ile bir yarışa ve bundan ötürü de bir çatışma içine girmelerine neden olur" (Glover 1993, 56). Bu çatışma ortamı, doğa durumunda, hiçbir etik ya da hukuki bir kural olmaması ve "insanların kendileri için neyin iyi neyin kötü olduğuna iliş̧kin kararlarının yine onların kendi değerlendirmelerine bağlı olması nedeniyle" (Warrender 1957, 210) sürdürülebilir bir duruma karşılık gelmez. Doğa durumunda, çatışmayı, bir başka deyişle, potansiyel bir savaş olasılığını ortadan kaldıracak bir gücün olmaması insanları doğal haklarını onlar adına koruyacak bir iktidar ya da egemen arayışına iter. Aslında, Hobbes'un doğa durumuna ilişkin tasarımı insanlara başka bir seçenek bırakmaz. Charvet'in de dile getirdiği gibi, "savaş durumu insanın doğasına içkin bir eğilim olarak toplumsal yaşamın olană̆ını ortadan kaldıran" (Charvet 1981, 41) ve bu nedenle de insanları zorunlu olarak bir devlet kurmaya iten bir olguya karşıllık gelir.

Görüldüğü üzere, Hobbes'un temel varsayımı, doğa durumunda insanların birbirleri ile kooperatif bir şekilde bir araya gelememeleri ve ortak çıkarları için hareket edememeleri üzerine yükselir. Ortak çıkarlar için eylemde bulunamıyor olmaları herkesin her şey üzerinde hak iddia etmesiyle sonuçlanır. Hobbes $(1991,91)$ bu durumu, Leviathan'da şu şekilde dile getirir. "İnsanin doğal durumu herkesin herkese karşı savaş durumu olduğu ve böyle bir durumda herkes kendi aklına uygun davrandı̆̆ için yaşamını düşmanlara karşı koruyabileceği hiçbir şey yoktur. Bu durum herkesin her şey üzerinde hakkı olduğu sonucunu doğurur”. Herkesin kendi 
aklına uygun davranması, bir başka deyişle, aklın sadece çıkarların korunması bağlamında kullanılması, kaçınılmaz olarak çıkarların çatıştığı bir ortama neden olacaktır. Bu nedenle, yine aklın kendi içinden türettiği doğa yasaları aracılığıyla herkes doğal haklarını kendi adına uygulama arzusundan vazgeçer ve onları kendi adlarına koruyacak bir egemene devrederse çatışma ortamından kurtulunur ve bir devlet kurabilmenin temel koşulu sağlanmış olur. Ancak burada, devlet kurma insanın doğasına içkin bir özellik olarak değerlendirilmemelidir. Bunun nedeni, Sommerville'in $(1992,40)$ de ifade ettiği gibi, "kendini ve sahip olduklarını koruyabilmenin başka bir yolunun olmamasıdır". O halde, insanları bir devlet kurmaya iten temel itki, ortak çıkarların korunmasından ziyade, bireysel çıkarların ortak çıkarlar üzerinden korunabileceği düşüncesidir. Böylesi bir düşünme tarzı, Hobbes açısından kabul edilebilir bir şeydir. Çünkü Hobbes için öncelik bireysel hak ve özgürlüklerin korunmasıdır. Devlet bu hakların korunması bağlamında siyasal ve toplumsal düzenin sağlayıcısı olarak bir anlam kazanır.

Hobbes, bireysel hak ve özgürlüklerin korunması amacıyla herkesin doğal haklarını onlar adına koruyacak bir egemen arayışına girmelerinin nedenini insan doğasına ilişkin karamsar düşünceleri üzerine kurgulamıştı. Bu karamsar tutum, aslında, onun oluşturmak istediği siyasal yapıya da, amaçları bakımından, uygundu. Onun temel argümanı, insanın doğal olarak çatışmacı, benci ve kötü olduğu üzerine kurgulanmıştı. Dolayısıyla, bu benci ve kötücül insanı uysallaştıracak, egemenin buyruklarına, haklarını koruduğu sürece uyacak bir yurttaş anlayışı başka türlü meşrulaştırılamazdı. Hobbes'un insan doğasına içkin olduğunu söylediği bencilik (bencillik değil), ötekilerin de aynı duyguyu paylaşıyor olduğu varsayımıyla kabul edilebilir görünüyor. Ancak buradan, insan sadece ve sadece kendi çıkarlarını düşünür sonucu çıkarılmamalıdır. Hiç kuşkusuz insan kendi çıkarlarını düşünür ancak bundan insan sadece ve sadece kendi çıkarlarını düşünür sonucu çıkmaz. İnsan, özgeci davranışlar da sergileyebilir. Ancak özgeci davranışlar gösteriyor olmak, insanın kendi çıkarlarını düşünmediği anlamına gelmez. Şunu söylemek istiyorum: İnsan doğasının benci ya da özgeci olduğu iddiası, her iki tanımlama bakımından, eşit derecede hem geçerlidir hem de geçerli değildir. Dikkat edilirse geçersizdir değil, geçerli değildir diyorum. Bu bağlamda, burada geçerli değildir ifadesi, sözü edilen özelliklerin insanda olmadığı anlamı çıkarılmasını engeller. Belki de, tam da bundan ötürü John Locke, Hobbes'un karamsar insan doğası tablosunu daha iyimser bir noktaya taşıma çabasına girmiştir.

Hobbes doğa durumunda insanların doğal halini barışçıl olmayan bir tutumla açıklamıştı. Sürekli bir çatışma hali ve bunun yarattığı korku hali insanların birbirlerine karşı güvensizlik duymasının temel nedeni olarak betimlenmişti. Locke, bu durumu tersine çevirme düşüncesiyle doğa durumunu barışçıl bir ortam olarak tasarlar. Locke da, Hobbes gibi, doğa durumu tasarımında insanların sınırsız özgürlükleri olduğunu dile getirir. Bu özgürlük, aynı zamanda, insanlar arasında bir eşitlik olduğu varsayımını da ortaya çıkarır. Aynı derecede bir özgürlük ve eşitlik düşüncesi insanların birbirleri üzerinde bir üstünlük kurma düşüncesi geliştirmelerini engeller. Locke $(1988,268)$ bu düşüncesini “aynı türün üyelerinin ayn olanaklara sahip olarak doğduğu ve birinin diğerinden daha aşağıda ya da yukarıda bir değere sahip olmadiğı" üzerine kurgular. İnsanların birbirleri ile aynı değere sahip varlıklar olarak tanımlanması, herkesin bir başkasının haklarını dikkate aldığı bir ortamın oluşmasına neden olur. Bu anlamda, özgürlük, sadece tek bir kişinin kendi eylemlerini istediği gibi uygulayacağı bir olanak sağlamaz, tersine herkesin özgürlüğünün dikkate alındığı, bir başka deyişle, başkalarının iradelerinin de dikkate alındığı bir eylem zorunluluğunu doğurur. Locke'a göre, bu zorunluluk, herkeste karş11ıklı bir saygı duygusunun ortaya çıkmasına da olanak sağlar. Ancak doğa durumunda varolduğunu söylediğimiz eşit ve özgür olma hali, doğanın herkese eşit davranmaması nedeniyle, bir çatışma ortamına da neden olabilir. Bu nedenle, Locke, kontrol edilebilir bir şey olmadığı düşüncesiyle özgürlüğün 
herkesin istediği gibi davranması anlamına gelmediğini söyler. Locke'un bu ifadesinin önemli bir nedeni var. Locke, mülkiyetin korunmasının koşulu olarak sınırsız özgürlük düşüncesini doğa yasaları ile sınırlandırmak istemektedir. Doğa yasaları herkesin herkesi dikkate aldığı bir ortamın temel koşulu olarak alınırken, bu koşul ile, aynı zamanda, doğa yasalarının ne zaman, hangi koşullarda insanın kendi çıkarları için kullanabileceğinin sınırları da çizilmiş oluyordu. Burada bir çelişki varmış gibi görünse de bu açıklama Locke'un tasarladığı sosyo-politik düzen ile uyum içindedir. Çünkü Locke için, mülkiyet sadece sahip olunan mal ve mülk anlamına gelmez. Onun için en önemli mülkiyet bedenin mülkiyetidir ve bu mülkiyet hiçbir zaman hiçbir şey için terk edilemez. O halde, beden mülkiyetinin korunması söz konusu olduğunda, insan doğa yasalarını kendi çıkarları için kullanabilir. Doğa yasalarını kendi çıkarlarına uygun olarak kullanabilme hakkının bedenin mülkiyetinin tehlikeye düştüğü durumlar olduğu varsayılsa da, burada asıl önemli olan şey, doğa durumunda sahip olunan hakların her koşulda sürekliliğinin sağlanmasıdır. Bu şu anlama gelir: Hobbes doğa durumundan sivil topluma geçişin koşulunu, doğal hakların egemene devredilmesi gerektiğine bağliyordu. Egemen, bu hakları korumakla yükümlüydü. Ancak Locke, Hobbes'tan farklı olarak, insanların hem sivil toplum öncesi hem de sonrasında sahip oldukları doğal hakları kullanma haklarının olduğunu dile getirmektedir. $\mathrm{Bu}$ aslında, her iki filozofun, zihinlerinde kurgulamak istedikleri sosyo-politik düzenin ipuçlarını vermektedir. Locke mutlak yetkilerle donatılmış bir egemenin ya da monarkın, insanları çıkmayı arzuladıkları doğa durumundan kurtarmak için yeterli olmadığı görüşünü ileri sürer. Oysa Hobbes'un kurguladığı sosyo-politik düzende sözleşme egemenle yapılmaz, egemen, insanların kendi aralarında yaptıkları sözleşmenin dışında kalır. Bu, bir bakıma, egemenin doğa durumunda sahip olduğu doğal hakları sözleşme sonrasında da kullanabileceği anlamına gelir. Aslında, bu durum, Hobbes'un kurguladığı düzen ile uyum içindendir. Çünkü o, egemenin mutlak güçlere sahip olmasını ve eylemlerinden sorumlu tutulmaması gerektiğini vurgular.

Doğal hakların devredilmesi konusunda, Locke Hobbes'un görüşlerini paylaşır ancak o hakların tek bir kişiye ya da topluluğa devredilmesini değil tüm topluma devredilmesi gerektiğini vurgular. Böylece, toplumun bütünü doğa yasasına aykırı eylemlerin cezalandırılmasının ya da ortadan kaldırılmasını aracı olur. Bu, aynı zamanda, eylemlerinden sorumlu olmayan bir egemen anlayışını da dışlamış olur ve kendileri için neyin iyi neyin kötü olduğuna, doğa yasalarının 1şı̆̆ında, toplumun tamamı karar vermiş olur (Locke 1998, 332). Oluşturulan sosyopolitik düzenin birliği ve sürekliliğinin çoğunluğun ortak kararına indirgenmiş ve herkesin barış ve güven içinde yaşama arzusunda olması nedeniyle de karmaşa ya da kaosun önüne geçilmiş olunur. Bu anlamda, Locke'un insan doğasına ilişkin tasarımı Hobbes'un dile getirdiği gibi kötü ve savaşçı değil, barışcıl ve uzlaşımcı olarak tanımlanabilir.

Machiavelli, Hobbes ve Locke üzerinde yürütmeye çalıştığım bu tartışmada insan doğası ve kurgulanmak istenen sosyo-politik düzen arasında doğrudan bir ilişki olduğunu göstermeye çalıştım. $\mathrm{Bu}$ yazıdaki temel amacım, hangi sosyo-politik düzenin toplumların kendi içlerinde ve diğer toplumlarla ilişkilerindeki mevcut çatışmaları ortadan kaldırmak için daha iyi olacağı tartışmasını yapmak değil, tersine bu tartışmayı yapabilmenin koşulu olarak insan doğası tasarımlarıyla kurulmak istenen düzen arasındaki ilişkiyi göstermekti. Bu nedenle, sözü edilen üç filozofun devlet kuramlarını inceleme çabasına girmedim. Bu, aynı zamanda, tarafsızlık ilkesinin gereği olarak herhangi birinin görüşünü savunma ihtiyacını da ortadan kaldırmış oldu. Ne var ki, bu yazıda, onlardan herhangi birinin tarafını tutmuyor olmam, insan doğası ve sosyo-politik düzen arasındaki ilişkiyi görmezden geliyor olduğum anlamına gelmez. İçinde bulunduğumuz dünyada hem demokrasi ile yönetilen ülkelerin iç sorunlarının, hem tek adam yönetimlerinin verdiği kararlara bağlı olarak ortaya çıkan hem iç hem de dış çatışmaların, insan doğası ve sosyo-politik düzen arasındaki içsel ilişkinin yeniden ele alınması gerektiğini yeterince gösterdiğini düşünüyorum. 


\section{KAYNAKÇA}

Charvet J. (1981). A Critique of Freedom and Equality. New York 1981.

Wilson F. G. (1946) "Human Nature and Politics". The Journal of Politics 8/4 (1946) 478-498.

Glover K. C (1993). "Human Nature and the State in Hobbes". Ed. P. King, Critical Assesments, Volume IV (1993) 50-72. London.

Hobbes T. (1987). De Cive. New York 1987.

Hobbes T. (1991). Leviathan. Cambridge 1991.

Hubbard R. (1990). "The Political Nature of 'Human Nature'. Ed. D. L. Rhode, Theoretical Perspectives on Sexual Differences (1990) 63-73. New Heaven.

Kavka G. S. (1986) Hobbesian Moral and Political Theory. New Jersey 1986.

Locke J. (1988). Two Treatises of Government. Cambridge 1988.

Machiavelli N. (1961). The Prince. USA 1961.

Machiavelli N. (1970). The Discourses. Trans. L. J. Walker. Harmondsworth 1970.

Sommerville J. P. (1992). Thomas Hobbes: Political Ideas in Historical Context. London 1992.

Warrender H. (1957). The Political Philosophy of Hobbes. New York 1957. 